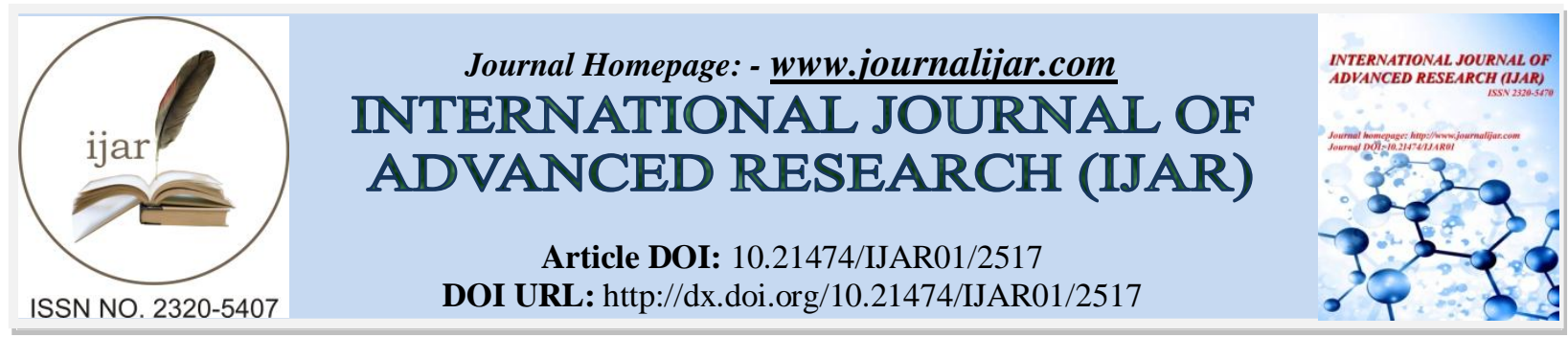

RESEARCH ARTICLE

\title{
KNOWLEDGE, ATTITUDES AND PRACTICES REGARDING BREASTFEEDING AMONG FEMALE SCHOOL TEACHERS AT QASSIM REGION.
}

\author{
Fahad A Alwusaydi ${ }^{1}$, Jalal A Bilal ${ }^{2}$, Mohannad S Alawad ${ }^{1}$ and Abdullah H Alharbi ${ }^{1}$. \\ 1. Medical Student, Qassim University. \\ 2. Assistant professor of Pediatrics, Pediatrics Department, College of Medicine, Qassim University.
}

\section{Manuscript Info}

..........................

Manuscript History

Received: 25 October 2016

Final Accepted: 23 November 2016

Published: December 2016

\section{Abstract}

Background: Breastfeeding is the ideal way of feeding infants, which has a great impact on them, their mothers, their health care costs and the whole society. It has many benefits for both the mother and the infant. The WHO recommends exclusive breastfeeding for up to 6 months of age, and to continue breastfeeding for two years or longer with proper complementary nourishments. Despite its benefits, breastfeeding rates and duration vary among countries and regions and the pattern have changed the changing community of Saudi Arabia. There are limited data regarding breastfeeding among female schoolteachers in Saudi Arabia. This study aimed to assess breastfeeding knowledge, attitude and practice of female schoolteachers in Qassim region, Saudi Arabia and to identify factors that affect breastfeeding knowledge, attitude and practice among them.

Methods: A cross-sectional study using a questionnaire was conducted among female schoolteachers Qassim Region, Saudi Arabia. Breastfeeding knowledge, attitude and practice of participants who had at least one child aged five years or younger at the time of the study was assessed with emphasis on their experience with the last child.

Results: A total of 526 women had an age range of 22 to 49 years. About 211 (41.2\%) women started breastfeeding their newborns after the first day while $124(24.2 \%)$ start feeding within half an hour after delivery. Child health was the main motivation for breastfeeding among $441(83.8 \%)$ of the respondents. Exclusive breastfeeding up to 6 months was reported in only $14(3 \%)$ of the participants. The main cause of early cessation of breastfeeding was insufficient breast milk, which was reported by $344(65.4 \%)$ of participants followed by work related reasons.

Conclusion: Although teacher mothers knew well about importance of breastfeeding to the child health, exclusive breastfeeding rate is very low. The most common cause of the early cessation of breastfeeding and early introduction of artificial milk was breast milk insufficiency. This is mostly due to inappropriate breastfeeding techniques and practices. Physicians and health care workers should emphasize the importance of exclusive breastfeeding and should 
explain the right techniques and practices of breastfeeding during pregnancy and early after delivery.

Copy Right, IJAR, 2016,. All rights reserved.

\section{Introduction:-}

Breastfeeding is the ideal way of feeding infants, which has a great impact on them, their mothers, their health care costs and the whole society (1). The WHO recommends exclusive breastfeeding for up to 6 months of age, and to continue breastfeeding for two years or longer with proper complementary nourishments (2).

Breastfeeding makes a significant emotional relationship and connections between the mother and her infant (3). It also has nutritional, developmental, immunological, and environmental benefits to the infant (4). The risk of some diseases like gastroenteritis, necrotizing enterocolitis, otitis media, respiratory infections, sudden infant death syndrome, obesity, and hypertension can be reduced by breastfeeding (5).

Numerous benefits for the breastfeeding mothers are well known in addition to those of the infant. Exclusive breastfeeding is more likely to cause amenorrhea, which conserves iron stores and reduces the risk of iron deficiency in the first 6 months postpartum (6). Extended breastfeeding has a suppressive effect on ovulation that delays the menstrual cycle and hence increases the duration between pregnancies (6). Breastfeeding mothers are less likely to have some types of cancers (7), especially breast and ovarian cancers (8). They have more weight and fat reduction compared to non-breastfeeding ones in short duration. As well, exclusive breastfeeding more than 6 months can cause more weight loss (9).

There are many variables affecting breastfeeding which includes; ethnicity, mother age and her education level, mother work, method of delivery, family support, weight gain and insufficient milk (10).

Despite all these benefits of breastfeeding, its prevalence and duration are lower than the recommendations in many countries (11). However there are rates variations from country to another. For example, in United Kingdom the rates of exclusive breastfeeding are increasing (12), while in United State the rates are stationary and low (13). In the Arabic countries there is a decline in the breastfeeding rate (14). In communities with rapid transition like Saudi Arabia the patterns of breastfeeding have changed (15), the rate was $31 \%$ in 2006 with continuing decrease (16). Progressive decrease in breastfeeding practice and duration was reported in Saudi Arabia (17). In addition early initiation of bottle-feeding and earlier introduction of solid foods was recorded (18).

Data on breastfeeding and factors affecting it attitudes were reported from different areas of Saudi Arabia (19). In a study done in Southwestern region of Saudi Arabia among female Saudi teachers the rate of exclusive breastfeeding for 6 months was found to be $8.3 \%$ (20). Female schoolteachers in Saudi Arabia represented half of the workforce and they will have a great effect on next generations (21).

The WHO definition of breastfeeding was that it is the way of providing infants with the nutrients and supplements they need for a proper health growth and development (22).

There are limited data regarding breastfeeding among female schoolteachers in Saudi Arabia. Furthermore no study was done in Qassim region about Knowledge, attitudes and practices of breastfeeding among female schoolteachers.

Our study aimed to assess breastfeeding knowledge, attitude and practice of female schoolteachers in Qassim region, Saudi Arabia and to identify factors that affect their knowledge, attitude and practice.

\section{Subjects and Methods:-}

This observational cross-sectional study was conducted among elementary, intermediate and secondary schoolteachers in the major cities of Qassim region, Middle of Saudi Arabia. The population of this study was 10127 female teachers from primary, middle and high school teaching almost 82736 students at 697 schools at Qassim region.

Female schoolteachers who had at least one child 5 years or younger at the time of the study were included while other school workers like administrative staff were excluded. 
The two-stage cluster sampling method was used. Primary sampling units were selected randomly from all the cities of Qassim. The cities were numbered and a computer-based random number generator was used to select target cities. In the Secondary sampling units female schools were numbered and a computer-based random number generator was used to select the schools from each city. It was anticipated that less than $20 \%$ of nursing mothers in the study population were exclusively breastfeeding. With an absolute precision of 5\% at 95\% confidence interval, the minimum sample size required for the study was calculated to be 492 mothers [23].

The questionnaires were distributed to 500 schoolteacher mothers in order to achieve a target of at least 492 participants.

A self-administered questionnaire was used to collect the data. The questionnaire was translated in Arabic. This questionnaire was adapted from the one used by Al-Binali (20). As well as the demographic and biological data, the questionnaire included questions addressing knowledge (importance of colostrum, the average number of feeds the child should receive per day, up to what age the child should receive only breast milk and what age the mother should start supplementary food), attitude (reasons for adopting breastfeeding, reasons for stopping breastfeeding, intention to breastfeed future children, intention to participate in classes related to breastfeeding in future pregnancy and the participant self-image) and practice (time of commencement of breastfeeding after delivery, duration of breastfeeding, difficulties in initiating breastfeeding, age of starting formula, age at which breastfeeding was stopped and attending classes related to breastfeeding during pregnancy). The questionnaire was initially validated through a pilot testing prior to administration.

Data were summarized and organized using SPSS software. Descriptive statistics was calculated including central tendency, the mean, and variability as indicated by measures of variance and standard deviation for continuous variables.

An informed consent was signed by all participants who were completely free whether to join the study or not and they had the right to withdraw from the study at any time without explaining the causes.

In this study the following definitions were used. Breastfeeding is the normal way of providing young infants with the nutrients they need for healthy growth and development. Colostrum is yellowish, sticky breast milk produced at the time before delivery. Exclusive breastfeeding: breast milk only, excluding water, other liquids, and solid foods (1).

\section{Results:-}

A total of 526 respondents was selected for this study. The mean \pm SD age of the interviewers was $35 \pm 5.64$ years with a range of 22-49 years. The majority of the respondent's educational level was University and teacher institutions among others. The school type of the majority of the respondent's was public. The remaining information about the characteristics of the members appears in Table 1.

Table 1:- schoolteachers demographic characteristic ( $N=526)$

\begin{tabular}{|l|l|l|}
\hline Variables & \multicolumn{2}{|l|}{} \\
\hline Age (Mean \pm SD), range & $(35 \pm 5.64), 22$ to 49 y \\
\hline Teacher Educational level & Frequency & $\mathbf{( \% )}$ \\
\hline Teacher institution & 18 & 3.5 \\
\hline High school "Tahfeedh" & 2 & 0.4 \\
\hline University & 439 & 84.7 \\
\hline Other & 59 & 11.4 \\
\hline School System & & \\
\hline Primary & 179 & 34.2 \\
\hline Intermediate & 80 & 15.3 \\
\hline High School & 264 & 50.5 \\
\hline Husband Education & & \\
\hline Primary & 25 & 4.9 \\
\hline Intermediate & 32 & 6.2 \\
\hline High School & 121 & 23.5 \\
\hline University & 337 & 65.4 \\
\hline Husband job: & & \\
\hline
\end{tabular}




\begin{tabular}{|c|c|c|}
\hline Unemployed & 45 & 8.7 \\
\hline Employed & 471 & 91.3 \\
\hline Living alone with husband: & 505 & 96.6 \\
\hline Number of Family members living together & \multicolumn{2}{|c|}{$\begin{array}{l}6 \pm 2 \\
\text { Min. } 0 \text { and Max. } 12\end{array}$} \\
\hline \multicolumn{3}{|l|}{ Do you have housemaid: } \\
\hline Yes & 308 & 58.7 \\
\hline No & 217 & 41.3 \\
\hline \multicolumn{3}{|l|}{ Type of Accommodation: } \\
\hline Apartment & 82 & 15.7 \\
\hline Floor & 121 & 23.2 \\
\hline Villa & 319 & 61.1 \\
\hline \multicolumn{3}{|c|}{ How do you see yourself in regards to weight and shape? } \\
\hline Thin & 25 & 4.8 \\
\hline Normal & 299 & 57.2 \\
\hline Somewhat Obese & 174 & 33.3 \\
\hline Obese & 25 & 4.8 \\
\hline \multicolumn{3}{|l|}{ Type of Delivery for the Last Child: } \\
\hline Normal & 361 & 70.8 \\
\hline Cesarean Section & 149 & 29.2 \\
\hline \multicolumn{3}{|c|}{ Did you have follow-up during the last pregnancy? } \\
\hline Yes & 496 & 97.4 \\
\hline No & 13 & 2.6 \\
\hline \multicolumn{3}{|l|}{ What is the gender of the youngest? } \\
\hline Male & 254 & 49.0 \\
\hline Female & 261 & 50.4 \\
\hline Twin "male and female" & 3 & 0.6 \\
\hline Mean age of the youngest child & \multicolumn{2}{|c|}{$3.018 \pm 2.3983$} \\
\hline Median age of the youngest child & \multicolumn{2}{|l|}{3} \\
\hline
\end{tabular}

Table 2 shows responding to frequency of breastfeeding, giving colostrum, artificial milk, the time of receiving breast milk with or without additive, and when to stop breast milk completely. The majority used to breastfeed as needed per day, and agree to provide colostrum after delivery. More information about the respondents' knowledge can be sought in the table.

Table 2:- schoolteachers' breastfeeding knowledge $(\mathrm{N}=526)$

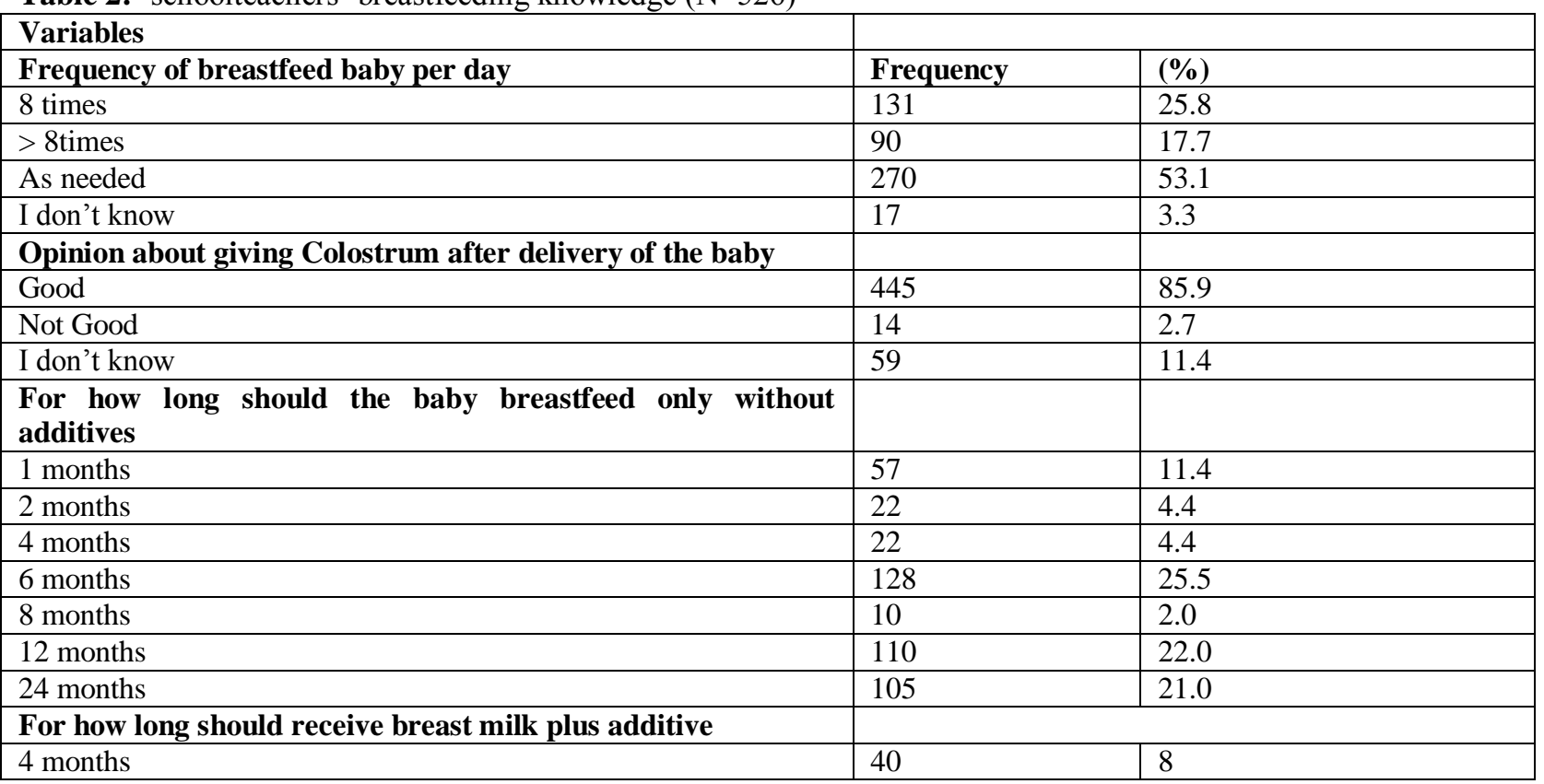




\begin{tabular}{|l|l|l|}
\hline 6 months & 181 & 36 \\
\hline 8 months & 29 & 5.8 \\
\hline 12 months & 83 & 16.5 \\
\hline 24 months & 102 & 20.3 \\
\hline
\end{tabular}

Information on schoolteachers' attitude towards breastfeeding incentive to practice, breastfeeding another successive child, and attendance of workshop regarding breastfeeding are summarized in figure1. Commencement of breastfeeding after delivery was noticed to be late in this cohort because most of respondents $\{416(80.0 \%)\}$ reported giving readymade formula to their babies despite the fact that the majority $\{267(51.4)\}$ hadn't face difficulties in initiating breastfeeding. Almost all respondents gave formula milk to their babies at a young age in correlation with cessation of breastfeeding in most of case due to insufficient breast milk (Table-3).

Figure 1:- breastfeeding attitudes of female schoolteachers $(\mathrm{N}=526)$

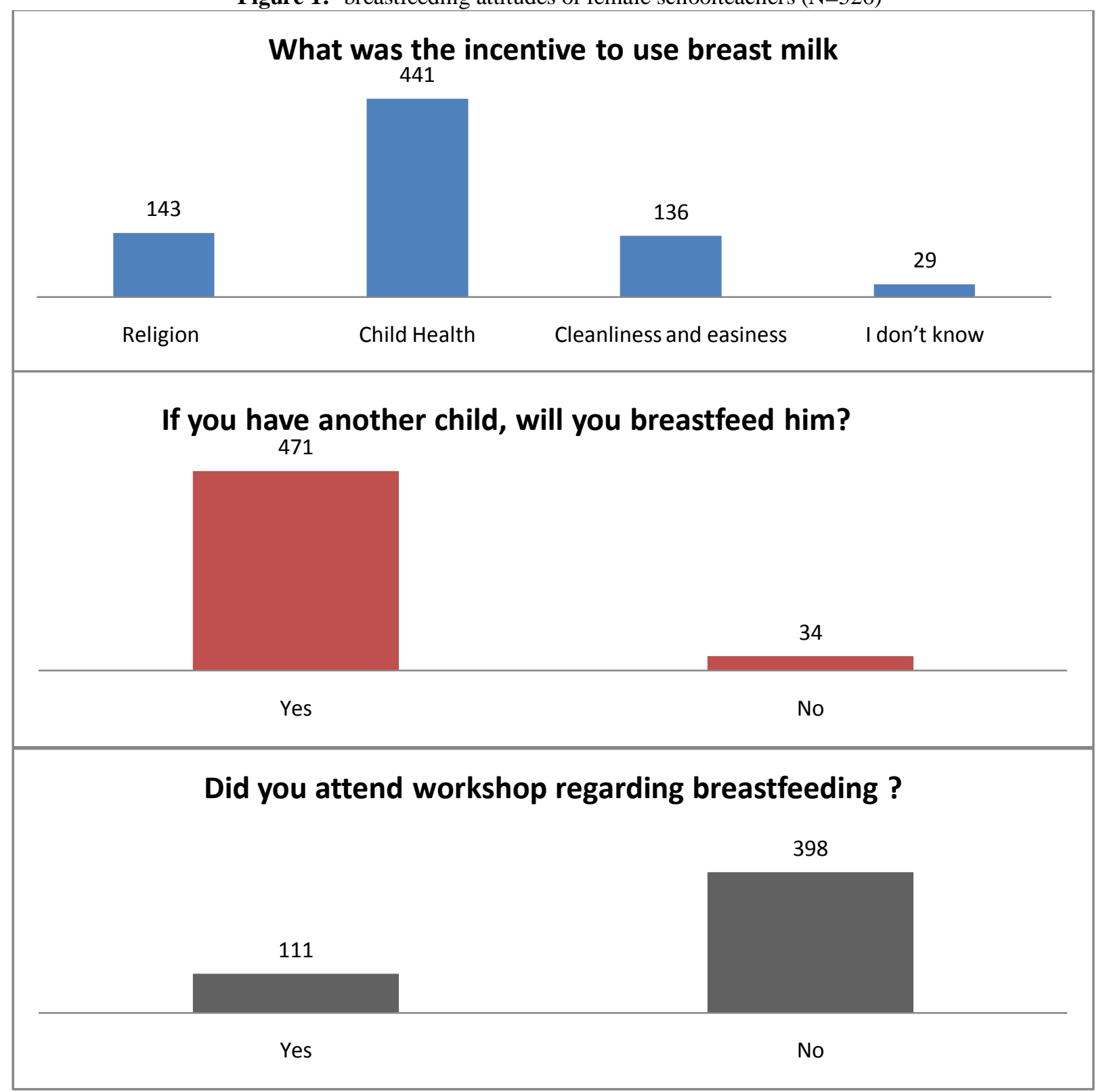




\section{If such workshop was made available to you in the future, will you attend?}

274

237

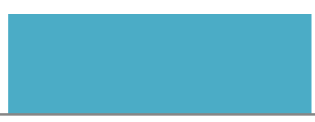

Yes

No

Table 3:- Breastfeeding practice by female schoolteachers

\begin{tabular}{|c|c|c|}
\hline Variables & Number & $(\%)$ \\
\hline \multicolumn{3}{|l|}{ When did you start breastfeeding? } \\
\hline $1 / 2$ hour after delivery & 124 & 24.2 \\
\hline Within 6 hours & 78 & 15.2 \\
\hline More than 6 hrs but within 24hours & 96 & 18.8 \\
\hline After the first day & 211 & 41.2 \\
\hline \multicolumn{3}{|c|}{$\begin{array}{l}\text { Did your child receive ready-made formula milk while in the } \\
\text { hospital? }\end{array}$} \\
\hline Yes & 416 & 80.8 \\
\hline No & 99 & 19.2 \\
\hline \multicolumn{3}{|l|}{ Do you face difficulty in breastfeeding? } \\
\hline Yes & 252 & 48.6 \\
\hline No & 267 & 51.4 \\
\hline \multicolumn{3}{|l|}{ Did you give artificial milk? } \\
\hline Yes & 475 & 91.9 \\
\hline No & 40 & 7.7 \\
\hline \multicolumn{3}{|l|}{ Baby age start artificial milk: } \\
\hline 1 months & 162 & 35.1 \\
\hline 2 months & 58 & 12.6 \\
\hline 3 months & \multicolumn{2}{|c|}{11.5} \\
\hline 4 months & 37 & 8.0 \\
\hline 6 months & 14 & 3.0 \\
\hline 12 months & 24 & 5.2 \\
\hline 24 months & 9 & 1.9 \\
\hline \multicolumn{3}{|c|}{ Age at which breast milk stopped completely: } \\
\hline 1 months & \multicolumn{2}{|c|}{12.4} \\
\hline 2 months & 61 & 12.4 \\
\hline 3 months & 49 & 10.0 \\
\hline 4 months & 51 & 10.4 \\
\hline 6 months & 63 & 12.8 \\
\hline 12 months & 51 & 10.4 \\
\hline 24 months & 39 & 7.9 \\
\hline \multicolumn{3}{|c|}{$\begin{array}{l}\text { If you stop breastfeeding before } 2 \text { years, what was the reason } \\
\text { behind that? }\end{array}$} \\
\hline Insufficient milk & 344 & 65.4 \\
\hline Child refusal & 121 & 23.0 \\
\hline Breast health problem & 36 & 6.8 \\
\hline Breastfeeding affects my shape & 9 & 1.7 \\
\hline Health problem & 75 & 14.3 \\
\hline Work related & 238 & 45.2 \\
\hline
\end{tabular}


A one-way ANOVA was used to identify the effects of the independent variables: duration of breastfeeding with or without additives, age of cessation of breast-feeding and age of commencement of artificial milk on educational level (university versus institute) as an independent variable. There was a significant effect of the age of infant at which breastfeeding was stopped on educational level $(\mathrm{F}=5.25, \mathrm{p}=0.001)$ as institutes graduates were tended to stop breastfeeding earlier than university graduates. All other factors were not significant effectors on educational level namely duration of breast-feeding without additives $(\mathrm{F}=1,61, \mathrm{p}=0.186)$, duration with additive $(\mathrm{F}=0.24, \mathrm{p}=0.869)$ and infant age at the start of artificial milk $(\mathrm{F}=0.591, \mathrm{p}=0.621)$.

Teacher mother's level of education was not significantly associated with follow-up during the last pregnancy $\left(\boldsymbol{X}^{2}=\right.$ $2.296, \mathrm{p}=0.513)$ and as well not with females' interest in the future available workshops $\left(\square \square^{2}=7.071, \mathrm{p}=0.070\right)$.

\section{Discussion:-}

In this study the majority of breastfeeding schoolteachers breastfeed their babies as needed. Most of them had good knowledge of colostrum and duration of breastfeeding with or without additives and their attitude towards breastfeeding is acceptable. However, breastfeeding was late to initiate instead artificial feeding was noticed despite good knowledge of breastfeeding benefits.

A study reported from Jeddah demonstrated that $56 \%$ of mothers had received breastfeeding instructions, generally by relatives [24] compared to this study, where 57.8\% of breastfeeding mothers had knowledge about the importance of breastfeeding from a doctor during antenatal care visits.

WHO recommends that all mother to breastfeed their babies within half an hour after delivery [25]. In this study only $124(24.2 \%)$ of mothers start breastfeeding within half an hour, comparable to $31 \%$ breastfed their babies within $1 / 2$ an hour in a study from Abha, Saudi Arabia [20].

The majority of the mothers believed that the primary incentive to practice breastfeeding was the child health while $27.2 \%$ were motivated by religion. This result was different from that reported from Abha, Saudi Arabia where $56.6 \%$ of mothers believed that the most important reason for initiating breastfeeding was their Islamic religious background [20].

The knowledge rate of exclusive breastfeeding for at least 6 months among mothers in this study, (25.5\%) was a little higher than the $22.0 \%$ rate in central Saudi Arabia [26]. Actually, in this study only 3\% continued exclusive breastfeeding for up to 6 months lower than the 8.3\% rate in Abha population [20].

Most of the participants in this study started artificial milk within the first month and approximately $53.1 \%$ of them breastfeed their baby as needed per day. These figures are lower than the rate in a study done among female health care workers in tertiary care hospitals [27]. The most common reason for stoppage of breastfeeding, in this study, was insufficient breast milk. This was similar to the most common reason in a systemic review in Saudi Arabia but different from a study done in Hail [28, 29] in which the main reason was mother's work.

The majority of breastfeeding teachers $(91.1 \%)$ used artificial milk to feed their babies during the first two years. This rate was higher than the $76.2 \%$ among health care workers in tertiary care hospitals [28]. The rate of readymade formula milk feeding (80.2\%) while in the hospital was higher than the 66.7\% rate in Abha study [20].

The rate of intention of breastfeeding future children (93.3\%), was more than the $84 \%$ rate in another study from Saudi Arabia [30].

Goodness of Colostrum to the infant was appreciated by $85.9 \%$ of participants in this study comparable to $89.3 \%$ reported among Abha population [20].

Almost 398 (77.9\%) of participants didn't attend workshops regarding breastfeeding, $57.8 \%$ obtained their knowledge about the importance of breastfeeding during antenatal care visits. These rates might contribute to the low rate of exclusive breastfeeding for 6 months, and to the high rate of initiation of artificial milk feeding during the first month of life. 


\section{Conclusion:-}

Although teacher mothers knew well about importance of breastfeeding to the child health, exclusive breastfeeding rate is very low. The most common cause of the early cessation of breastfeeding and early introduction of artificial milk was breast milk insufficiency. This is mostly due to inappropriate breastfeeding techniques and practices. Physicians and health care workers should emphasize the importance of exclusive breastfeeding and should explain the right techniques and practices of breastfeeding during pregnancy and early after delivery.

\section{References:-}

1. World Health Organization. Planning guide for national implementation of the global strategy for infant and young child feeding. World Health Organization; 2007.

2. WHO | Exclusive breastfeeding for six months best for babies everywhere [Internet]. Who.int. 2011 [cited 25 November 2016]. Available from: http://www.who.int/mediacentre/news/statements/2011/breastfeeding_20110115/en/

3. Asaei M, Esfehani MM, Oladi B, Bahrami M, Parsai S, Khatami Gh R, et al. What we should know about infant feeding. A guide for mother \& health professionals. World Health Organization (WHO) \& IRI Breastfeeding Promotion Society; 1999

4. American Academy of Pediatrics Work group on breastfeeding: breastfeeding and the use of human milk Pediatrics, 100 (1997), pp. 1035-1039

5. James DC, Lessen R, Position of the American Dietetic Association: Promoting and Supporting Breastfeeding. Journal of the American Dietetic Association. 2009;109(11):1926-1942.

6. Dewey KG, Cohen RJ, Brown KH, and Rivera LL. Effects of exclusive breastfeeding for 4 vs 6 months on maternal nutritional status and infant motor development: Results of two randomized trials in Honduras. J Nutr. 2001;131:262-267.

7. Breastfeeding: MedlinePlus [Internet]. Medlineplus.gov. 2016 [cited 25 November 2016]. Available from: https://medlineplus.gov/breastfeeding.html

8. Breast cancer and breastfeeding: collaborative reanalysis of individual data from 47 epidemiological studies in 30 countries, including 50302 women with breast cancer and 96973 women without the disease. The Lancet. 2002;360(9328):187-195.

9. Kac G, Benicio M, Velásquez-Meléndez G, Valente J. Nine months postpartum weight retention predictors for Brazilian women. Public Health Nutrition. 2004;7(05).

10. Thulier DMercer J. Variables Associated With Breastfeeding Duration. Journal of Obstetric, Gynecologic \& Neonatal Nursing. 2009;38(3):259-268.

11. Foo L. Breastfeeding prevalence and practices among Singaporean Chinese, Malay and Indian mothers. Health Promotion International. 2005;20(3):229-237.

12. Infant feeding survey [Internet]. 2012 [cited 25 November 2016]. Available from: http:// www.unicef.org.uk/Documents/Baby_Friendly/Statements/IFS_Survey_Summary_211112.pdf.

13. Breastfeeding Report Card - United States, 2010 [Internet]. CDC. 2010 [cited 25 November 2016]. Available from: http://www.cdc.gov/breastfeeding/pdf/BreastfeedingReportCard2010.pdf.

14. Musaiger AO. Breastfeeding patterns in the Arabian Gulf countries. World Rev Nutr Diet 1995; 78: 164e190.

15. Al-Nahedh NMorley D. Infant Feeding Practices and the Decline of Breast Feeding in Saudi Arabia. Nutrition and Health. 1994;10(1):27-31.

16. Al-Mazrou Y, Aziz K, Khalil M. Breastfeeding and Weaning Practices in Saudi Arabia. Journal of Tropical Pediatrics. 1994;40(5):267-271.

17. El Mouzan M, Al Omar A, Al Salloum A, Al Herbish A, Qurachi M. Trends in infant nutrition in Saudi Arabia : Compliance with WHO recommendations. Annals of Saudi Medicine. 2009;29(1):20.

18. Al-Jassir MS, El-Bashir BM, Mouziddin SK. Surveillance of infant feeding practices in Riyadh city. Ann Saudi Med 2004;24:136-140.

19. Al-Jassir M, Khaja Moizuddin S, Al-Bashir B. A Review of some Statistics on Breastfeeding in Saudi Arabia. Nutrition and Health. 2003;17(2):123-130.

20. Al-Binali A. Breastfeeding knowledge, attitude and practice among school teachers in Abha female educational district, southwestern Saudi Arabia. Int Breastfeed J. 2012;7(1):10.

21. Annual report of central department of statistics and information [Internet]. Moe.gov.sa. 2009 [cited 25 November 2016]. Available from: http://www.moe.gov.sa/Pages/stats31-32.aspx.

22. Global strategy for infant and young [Internet]. Who.int. 2001 [cited 25 November 2016]. Available from: http://www.who.int/nutrition/topics/infantfeeding_recommendation/en/ 
23. Lachenbruch P, Lwanga S, Lemeshow S. Sample Size Determination in Health Studies: A Practical Manual. Journal of the American Statistical Association. 1991;86(416):1149.

24. Fida NM, Al-Aama JY: Pattern of infant feeding at a university hospital in Western Saudi Arabia. Saudi Med J. 2003, 24: 725-729.

25. Ten Steps to Successful Breastfeeding [Internet]. Unicef.org. [cited 25 November 2016]. Available from: http://www.unicef.org/newsline/tenstps.htm

26. Yazeed A. Alwelaie,e, Eyas A. Alsuhaibani, Abrar M. Al-Harthy, Reem H. Radwan, Rawan G. AlMohammady, Ahmed M. Almutairi, Breastfeeding knowledge and attitude among Saudi women in Central Saudi Arabia, Saudi Med J 2010; Vol. 31

27. Al-Binali A. Knowledge, attitude and practice of Breast-Feeding among female health care workers in tertiary care hospitals, The Medical Journal of Cairo University. 2012; 80(2)

28. Al Juaid D, Binns C, Giglia R. Breastfeeding in Saudi Arabia: a review. Int Breastfeed J. 2014;9(1):1.

29. Shommo SAl-Shubrumi H. Breastfeeding knowledge, attitude and practice among mothers in Hail district, northwestern Saudi Arabia. IOSR Journal of Nursing and Health Science. 2014;3(1):49-56.

30. Al-Madani M, Vydelingum V, Lawrence J. Saudi Mothers' Expected Intentions and Attitudes Toward BreastFeeding. ICAN: Infant, Child, \& Adolescent Nutrition. 2010;2(3):187-198. 